\title{
METODE OPTIMASI PADA SISTEM PENGENDALIAN PROSES TANGKI PEMANAS BERPENGADUK
}

\author{
Rudy Agustriyanto \\ Jurusan Teknik Kimia, Fakultas Teknik, Universitas Surabaya, Jl. RayaKalirungkut, Surabaya, 60293, Indonesia \\ Email: rudy.agustriyanto@staff.ubaya.ac.id
}

\begin{abstract}
Abstrak
Pada penelitian ini, penyetelan pengendali PID (Proportional Integral Derivative) dilakukan dengan metode optimasi dan hasil akhirnya dibandingkan dengan metode penyetelan lain (yaitu metode sintesa langsung dan Ziegler-Nichols). Tujuan penelitian adalah mendapatkan response output terbaik ketika terjadi perubahan set point dan terjadi gangguan. Penyetelan pengendali adalah proses yang berguna dalam menetapkan parameter pengendali yang dapat mempengaruhi response output dari perubahan setpoint (masalah servo) maupun ketika terjadi gangguan (masalah regulatori). Kinerja pengendali dapat dievaluasi dari harga SSE (Sum Squares of Error) ketika sistem dikendalikan oleh pengendali PID yang disetel dengan metode tertentu. Hasil penelitian menunjukkan bahwa metode optimasi tampak lebih baik dari metode lainnya karena memberikan kinerja terbaik.
\end{abstract}

Kata kunci: Optimasi, Penyetelan, Pengendali PID

\begin{abstract}
In this research, PID (Proportional Integral Derivative) controller tuning was done using optimization method and the result was compared to the other well-known tuning methods (Direct synthesis, Ziegler- Nichols). The purpose of this research is to obtain the best output response when the set point and disturbance are changed. Tuning is a useful process to set the controller parameter that can affect the output response from the changing set point (servo problem) as well as from the disturbance (regulatory problem). The controller performance can be evaluated from the value of Sum Squares of Error when the system is controlled by PID controllers that is tuned with chosen method. The research result showed that optimization method was better than the other methods because it could give the best result.
\end{abstract}

Keywords: Optimization, Tuning, PID control

\section{Pendahuluan}

Optimasi bisa digunakan dalam berbagai bidang yaitu baik dalam bidang ilmu pengetahuan, teknik, dan bisnis. Dalam bidang statistik berbagai prinsip optimasi akan menghasilkan keuntungan maksimum, dan kerugian minimum, sementara di bidang bisnis metode optimasi digunakan untuk memaksimalkan keuntungan dan meminimalkan biaya dengan menggunakan sumber daya semaksimum mungkin menggunakan usaha seminimal mungkin dalam upaya untuk meningkatkan keuntungan bisnis. Dalam bidang teknik metode ini dapat digunakan untuk menafsirkan beberapa persamaan.

Penggunaan metode optimasi ini mulai banyak di gunakan pada pengendali PID. Pada optimasi, pengendali PID termasuk pengendali konvensional atau klasik yang masih populer di industri hingga saat ini karena efektifitasnya luar biasa, implementasinya mudah dan aplikasinya sangat luas. Seiring dengan perkembangan teknologi, mulai dikembangkan pengendali modern, seperti nonlinear control, optimal control, variable structure control, adaptive control. Masalah utama pengendali PID adalah penyetelan,yaitu menentukan nilai parameter $\mathrm{kc}, \tau \mathrm{i}$ dan $\tau$ d agar diperoleh performa sistem yang optimal [6].

Penelitian ini digunakan untuk mendapatkan nilai penyetelan pengendali proses orde satu dari sistem tangki pemanas berpengaduk yang terbaik menggunakan metode optimasi jika dibandingkan dengan metode konvensional lain.

Penelitian yang dilakukan Tavakoli menggunakan analisis dimensi dan teknik optimasi numerik membuktikan bahwa metode yang optimal untuk penyetelan pengendali PID untuk proses orde satu dengan time delay ditampilkan dengan mempertimbangkan nilai Integral Square Error (ISE), Integral Absolute Error (IAE) dan Integral Time Absolute Error (ITAE). Hasil simulasi menunjukkan bahwa metode yang diusulkan memiliki keunggulan besar jika dibandingkan dengan teknik konvensional [6].

Metode penyetelan dapat menawarkan perkiraan awal nilai parameter pengendali PID. Namun tujuan perancangan yang digunakan untuk pengembangan dari metode penyetelan dapat menjadi sangat berbeda dari tujuan kinerja spesifik untuk proses yang diselidiki. Akibatnya, insinyur pengendali sering menyesuaikan kebutuhan untuk merancang suatu sistem lintas tertutup yang memuaskan. Diusulkan 
sebuah reformulasi dari rumusan matematika, yang mengubah rumusan awalnya non - linear untuk menjadi linear yang dapat menyelesaikan permasalahan optimasi secara global [5].

Algoritma auto - tuning untuk pengendali PI dan PID berdasarkan pengulangan percobaan yang pernah dilakukan diusulkan untuk meminimalkan kesalahan gangguan integral error (IE) dengan memaksimalkan integral gain, keuntungan subyek ke fasa yang diinginkan dan meminimalkan batasan gain yang diperlukan. Keuntungan utama dari algoritma auto - tuning untuk penyetelan pengendali PID dengan sistem lintas tertutup mirip dengan pengendali PID yang dirancang menggunakan optimasi numerik off-line. Selain itu algoritma ini berlaku untuk setiap struktur model linier, termasuk dead time dan sistem fase non-minimum [3].

\section{Teori}

Optimasi merupakan salah satu metode kuantitatif utama sebagai sarana pengambilan keputusan [2]. Optimasi berfokus pada pemilihan sesuatu yang paling baik dari keseluruhan rangkaian dengan menggunakan suatu metode kuantitatif. Berbagai macam masalah pada desain, konstruksi, operasi, dan analisa pada pabrik kimia dapat diselesaikan dengan optimasi. Masalah yang terjadi dalam bidang teknik dapat direpresentasikan oleh suatu persamaan atau mungkin sebuah data dari hasil eksperimen. Optimasi digunakan dengan tujuan menentukan nilai variabel dalam proses yang dapat menghasilkan kriteria performa kerja terbaik.

Dalam pabrik kimia, keuntungan dapat diperbesar dengan menaikkan performa kerja pabrik tersebut, misalnya dengan meningkatkan nilai yield dari produk yang diinginkan dan berdaya jual, mengurangi konsumsi energi yang digunakan, mempercepat laju pemrosesan, dan pengupayaan waktu yang lebih lama antara tiap proses shutdown. Optimasi berfungsi untuk mengurangi biaya perawatan alat, mengurangi jumlah peralatan yang digunakan, dan dapat mereorganisasi penggunaan sumber daya manusia agar lebih efisien.

Cakupan penerapan optimasi dalam suatu masalah dapat meliputi keseluruhan perusahaan, pabrik, proses ataupun unit operasi tunggal, satu bagian dari suatu peralatan, dan sebagainya. Dalam proses optimasi ini dikenal pula istilah program simulator desain proses yang merupakan suatu alat bantu untuk pemecahan masalah dalam industri. Program ini dapat melaksanakan perhitungan neraca massa dan energi untuk tiap-tiap bagian dari suatu peralatan dan kemudian mengkombinasikannya menjadi suatu unit produksi total. Penggunaan fungsi iterasi untuk simulasi semacam ini biasanya sangat diperlukan terutama untuk mencapai diagram alir proses yang diinginkan.

Ada 2 data penting yang diperlukan dalam mengindetifikasi suatu proses optimasi yaitu: data tentang keuntungan dan harga dari suatu pabrik atau masing-masing unit yang berada di dalamnya, dan data tentang catatan periodik dari sistem operasi yang bekerja dalam suatu pabrik tersebut. Catatan tersebut berisikan informasi mengenai neraca massa dan energi sistem, efisensi, kualitas dan kuantitas produk yang dihasilkan, dan jumlah umpan masuk yang tersedia.

Tiap masalah optimasi memiliki 3 komponen penting yaitu:

1. Setidaknya terdapat satu fungsi yang akan dioptimalkan (misalnya fungsi keuntungan, fungsi biaya, dan sebagainya)

2. Batasan persamaan (persamaan)

3. Batasan pertidaksamaan (pertidaksamaan)

Langkah-langkah untuk memecahkan masalah optimasi:

1. Menganalisa proses itu sendiri sehingga variabel proses dan karakter-karakter spesifik lainnya dapat terdefinisi.

2. Menentukan kriteria optimasi dan membuat spesifik fungsi yang diinginkan untuk dinyatakan dalam variabel-variabel dan konstanta-konstanta yang telah didefinisikan di atas. Langkah ini menyediakan suatu performance model.

3. Mengembangkan model matematis dari proses atau peralatan tersebut yang menunjukkan hubungan antara variabel input-output dari proses dan juga koefisien-koefisien yang berhubungan dengan variabel-variabel tersebut. Selain itu, perlu disertakan juga batasan dalam persamaan dan pertidaksamaan yang digunakan. Dapat dipakai juga konsep-konsep neraca massa dan energi, persamaan empiris, konsep implisit dan batasanbatasan eksternal. Kemudian melakukan identifikasi variabel dependent dan variabel independent untuk memperoleh jumlah degree of freedom.

4. Jika jangkauan masalah terlalu luas maka dapat dilakukan pemecahan problem tersebut menjadi bagian-bagian yang lebih kecil atau membuat fungsi obyektif menjadi model yang lebih sederhana.

5. Menerapkan teknik optimasi yang sesuai dengan model matematika yang ada.

6. Memeriksa kembali jawaban yang diperoleh, dan menyelidiki pengaruh hasil terhadap koefisienkoefisien dalam masalah serta bentuk-bentuk asumsi yang mungkin digunakan.

Masalah optimasi dapat menemui kendala atau mungkin kegagalan yang disebabkan oleh:

1. Fungsi obyektif dan atau fungsi pembatas kemungkinan mempunyai daerah diskontinu dalam parameter kontinu yang dipakai.

2. Fungsi obyektif dan atau fungsi pembatas kemungkinan bukan suatu fungsi linear terhadap variabel-variabelnya. 
3. Fungsi obyektif dan atau fungsi pembatas kemungkinan didefinisikan dalam bentuk interaksi antar variabelnya yang terlalu rumit.

4. Nilai dari Fungsi obyektif dan atau fungsi pembatas termasuk tidak sensitif, atau justru terlalu sensitif terhadap perubahan dari variabelvariabel yang ada.

5. Fungsi obyektif menunjukkan suatu kondisi optimum lokal saat kondisi optimum global dicapai.

\section{Metodologi Penelitian}

Matlab dan Simulink digunakan untuk melakukan simulasi proses dan implementasi sistem pengendaliannya. Adapun sistem yang ditinjau adalah sistem tangki pemanas berpengaduk seperti ditunjukkan pada Gambar 1.

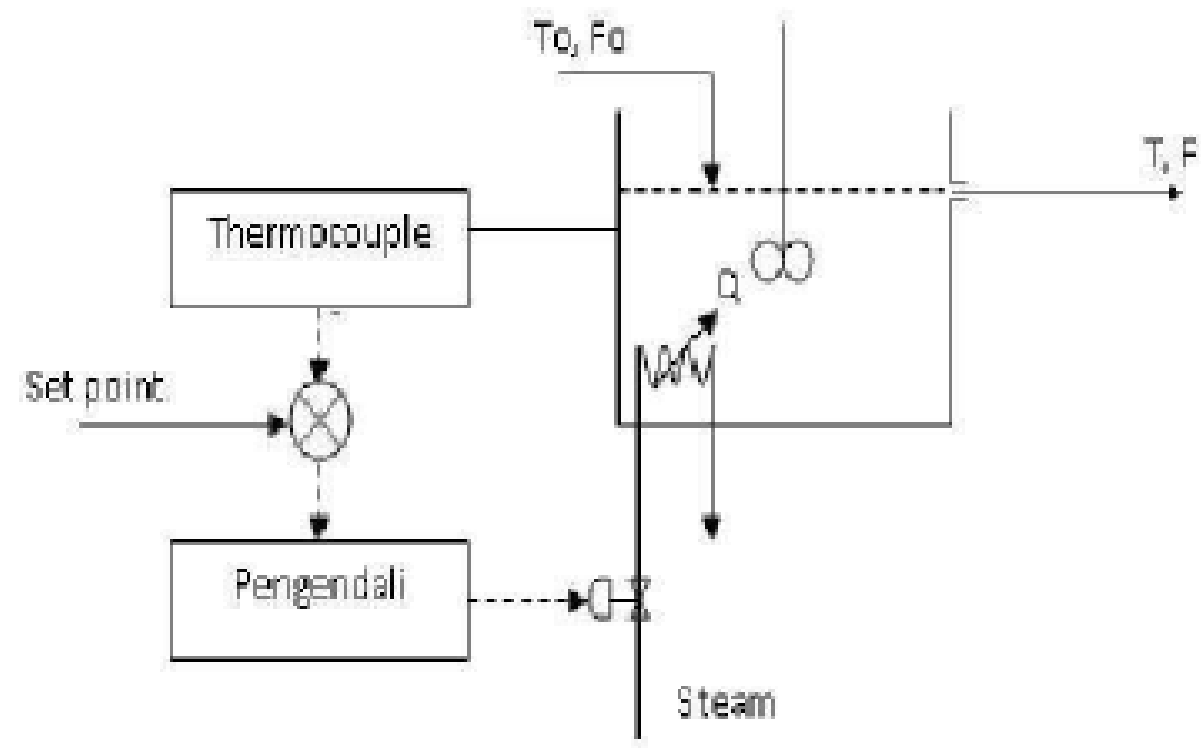

Gambar 1. Sistem tangki pemanas berpengaduk

Pada sistem tangki pemanas di atas air masuk pada suhu To (K) dengan laju alir volumetric Fo (m3/menit). Air yang masuk dalam tangki tersebut diinginkan memiliki suhu $\mathrm{T}(\mathrm{K})$ saat keluar tangki. Hal ini dapat dilakukan dengan suplai panas yang berasal dari steam yang dialirkan dalam koil. Pada sistem dipasang thermocouple sebagai sensor untuk mengetahui suhu air di dalam tangki, untuk selanjutnya thermocouple akan membandingkan apakah suhu dalam tangki sudah sama dengan suhu set point. Selisih dari pembacaan thermocouple dan suhu set-point akan mempengaruhi kerja pengendali yang akan mengatur bukaan valve supaya steam yang disuplai sesuai untuk mencapai suhu keluar (T) yang diinginkan.

Fungsi hantar untuk sistem ini telah diturunkan dengan menggunakan neraca massa dan panas [1], dan diperoleh hasil sebagai berikut [7]:

- Antara output T dengan gangguan To adalah:

$$
\frac{\bar{T}(s)}{\overline{T o}(s)}=\frac{1}{\left(\frac{V}{F o} \cdot s+1\right)}
$$

- Antara output T dengan Q adalah:

$$
\frac{\bar{T}(s)}{\bar{Q}(s)}=\frac{\frac{1}{\rho \cdot c p \cdot F o}}{\left(\frac{V}{F o} \cdot s+1\right)}
$$

Dimana :

- $\quad$ Fungsi transfer sensor (thermocouple) $=1$

- $\quad$ Fungsi transfer pengendali valve $=1$

- $\rho=$ Massa jenis $\left(\mathrm{kg} / \mathrm{m}^{3}\right)$

- $\mathrm{A}=$ Luas permukaan tangki $\left(\mathrm{m}^{2}\right)$

- $\mathrm{h}=$ Ketinggian tangki (m)

- $\mathrm{t}=$ Waktu (menit)

- $\quad F o=$ Laju alir masuk $\left(\mathrm{m}^{3} /\right.$ menit $)$

- $\mathrm{F}=$ Laju alir keluar $\left(\mathrm{m}^{3} /\right.$ menit $)$

- $\mathrm{T}=$ Suhu keluar $(\mathrm{K})$

- $\mathrm{To}=$ Suhu masuk $(\mathrm{K})$

- $\mathrm{Q}=$ Kalor yang disuplai (kJ/menit)

- $\quad \mathrm{cp}=$ Heat capacity $(\mathrm{kJ} / \mathrm{kg} . \mathrm{K}$ 
Fungsi hantar tersebut kemudian disimulasikan dengan Simulink dan dibuat lintas tertutup dengan pengendali PID. Diagram blok untuk sistem lintas tertutup dapat dilihat pada Gambar 2. Sedangkan skema penyetelan pengendali PID dengan metode optimasi ditunjukkan pada Gambar 3.

Dari Gambar 2, dapat ditentukan rumus untuk gain proses $(\mathrm{Kp})$ dan time constant proses $(\tau)$ adalah:

$$
\begin{aligned}
& K_{p}=\frac{1}{\rho \cdot c p \cdot F o} \\
& \tau=\frac{V}{F o}
\end{aligned}
$$

Sedangkan waktu tunda $(\theta)$ yang terjadi pada proses di atas, diasumsikan sebesar 1 menit.

Dalam penelitian ini dilakukan penyetelan pengendali untuk beberapa variabel percobaan seperti ditunjukkan pada Tabel 1 .

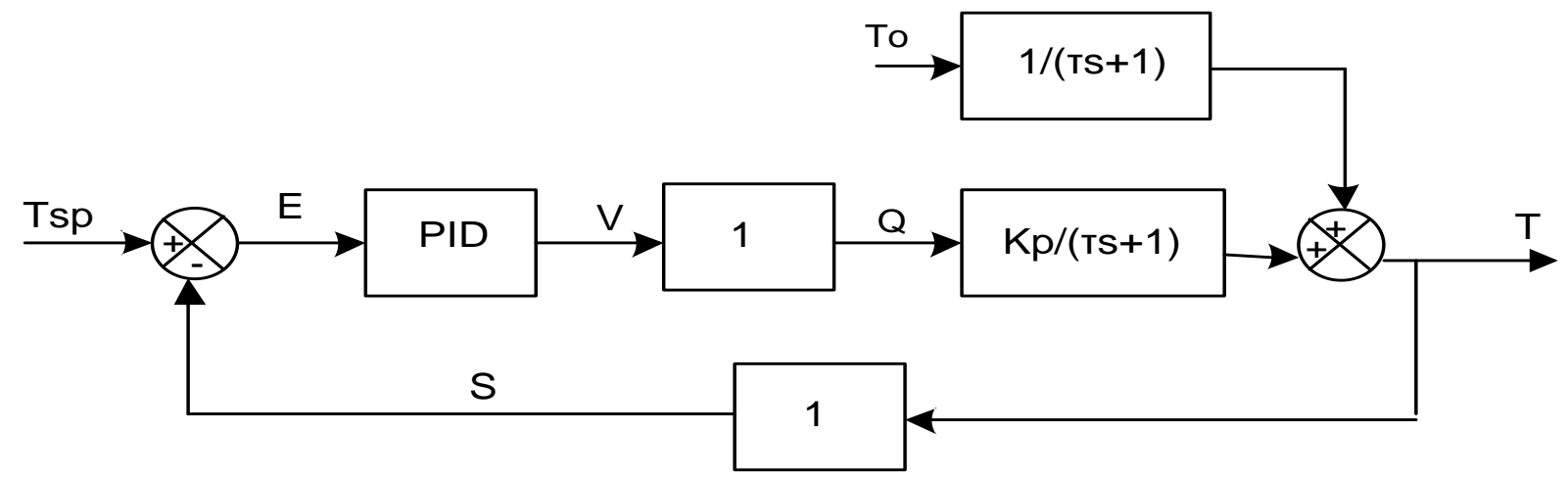

Gambar 2. Diagram blok sistem lintas tertutup

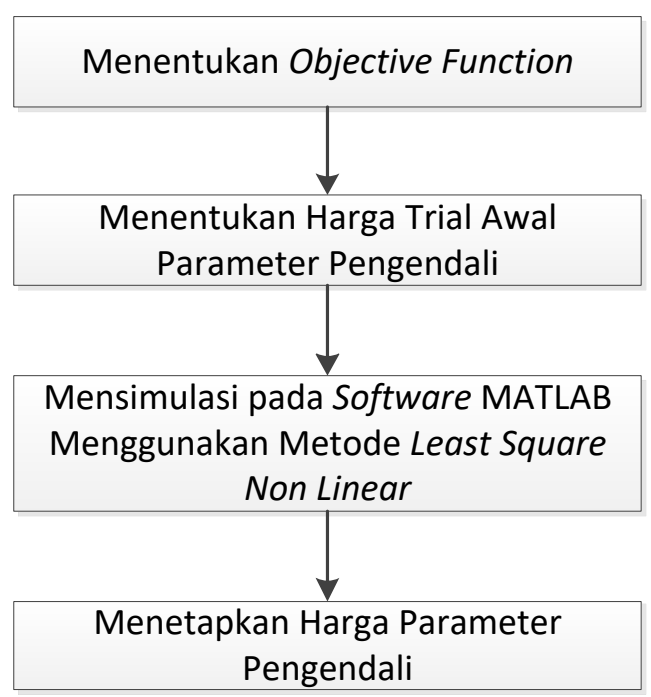

Gambar 3. Skema penyetelan dengan metode optimasi 
Tabel 1. Data Variabel Proses

\begin{tabular}{|c|c|c|}
\hline Simulasi No & Variabel proses & Harga Parameter Model \\
\hline 1 & $\begin{array}{l}\mathrm{V}=25 \mathrm{~m}^{3} \\
\mathrm{Fo}=5 \mathrm{~m}^{3} / \text { menit } \\
\text { To }=303,15 \mathrm{~K} \\
\rho=995,68 \mathrm{~kg} / \mathrm{m}^{3} \\
\mathrm{cp}=4,181 \frac{\mathrm{kJ}}{\mathrm{kg} \cdot \mathrm{K}}\end{array}$ & $\begin{array}{l}\mathrm{Kp}=4,804 \cdot 10^{-5}\left(\frac{K \cdot \text { menit }}{k J}\right) \\
\tau=5 \text { menit } \\
\theta=1 \text { menit }\end{array}$ \\
\hline 2 & $\begin{array}{l}\mathrm{V}=35 \mathrm{~m}^{3} \\
\mathrm{Fo}=6 \mathrm{~m}^{3} / \text { menit } \\
\text { To }=303,15 \mathrm{~K} \\
\rho=995,68 \mathrm{~kg} / \mathrm{m}^{3} \\
\mathrm{cp}=4,181 \frac{\mathrm{kJ}}{\mathrm{kg} \cdot \mathrm{K}}\end{array}$ & $\begin{array}{l}\mathrm{Kp}=4,036 \cdot 10^{-5}\left(\frac{K \cdot \text { menit }}{k J}\right) \\
\tau=5,8333 \text { menit } \\
\theta=1 \text { menit }\end{array}$ \\
\hline 3 & $\begin{array}{l}\mathrm{V}=40 \mathrm{~m}^{3} \\
\text { Fo }=5 \mathrm{~m}^{3} / \text { menit } \\
\text { To }=303,15 \mathrm{~K} \\
\rho=995,68 \mathrm{~kg} / \mathrm{m}^{3} \\
\mathrm{cp}=4,181 \frac{\mathrm{kJ}}{\mathrm{kg} \cdot \mathrm{K}}\end{array}$ & $\begin{array}{l}\mathrm{Kp}=4,804 \cdot 10^{-5}\left(\frac{K \cdot \text { menit }}{k J}\right) \\
\tau=8 \text { (menit) } \\
\theta=1 \text { menit }\end{array}$ \\
\hline 4 & $\begin{array}{l}\mathrm{V}=40 \mathrm{~m}^{3} \\
\mathrm{Fo}=8 \mathrm{~m}^{3} / \text { menit } \\
\mathrm{To}=303,15 \mathrm{~K} \\
\rho=995,68 \mathrm{~kg} / \mathrm{m}^{3} \\
\mathrm{cp}=4,181 \frac{\mathrm{kJ}}{\mathrm{kg} \cdot \mathrm{K}}\end{array}$ & $\begin{array}{l}\mathrm{Kp}=3,002.10^{-5}\left(\frac{K \cdot \text { menit }}{k J}\right) \\
\tau=5 \text { (menit) } \\
\theta=1 \text { menit }\end{array}$ \\
\hline 5 & $\begin{array}{l}\mathrm{V}=50 \mathrm{~m}^{3} \\
\text { Fo }=8 \mathrm{~m}^{3} / \text { menit } \\
\text { To }=303,15 \mathrm{~K} \\
\rho=995,68 \mathrm{~kg} / \mathrm{m}^{3} \\
\mathrm{cp}=4,181 \frac{\mathrm{kJ}}{\mathrm{kg} \cdot \mathrm{K}}\end{array}$ & $\begin{array}{l}\mathrm{Kp}=3,002.10^{-5}\left(\frac{K \cdot \text { menit }}{k J}\right) \\
\tau=6,25 \text { (menit) } \\
\theta=1 \text { menit }\end{array}$ \\
\hline
\end{tabular}

\section{Hasil}

Nilai parameter pengendali PID ( $\mathrm{kc}, \tau \mathrm{i}, \tau \mathrm{d})$ untuk sistem yang disetel dengan metode optimasi ditunjukkan pada Tabel 2. Gambar 4 s.d 8 menunjukkan profil output $\mathrm{T}$ dan kalor $\mathrm{Q}$ pada perubahan set point maupun perubahan gangguan To untuk kelima sistem yang ditinjau.

Pengujian pada Sistem no. 1 (Simulasi no 1) dilakukan dengan perubahan set point berupa fungsi step dari suhu $345,15 \mathrm{~K}$ menjadi $362,15 \mathrm{~K}$ pada waktu $\mathrm{t}=1$ menit dilanjutkan berubah menjadi 347,15 pada waktu $\mathrm{t}=75$ menit dan berubah lagi menjadi $357,15 \mathrm{~K}$ pada $\mathrm{t}=120$ menit serta adanya gangguan sebagai perubahan suhu air masuk (To) berupa fungsi step dari suhu $303,15 \mathrm{~K}$ menjadi $318,15 \mathrm{~K}$ pada $\mathrm{t}=30$ menit lalu berubah menjadi $293,15 \mathrm{~K}$ pada $\mathrm{t}=95$ menit. Profil sistem lintas tertutup dapat dilihat pada Gambar 4.

Kemudian pada Sistem 2 (Gambar 5) juga dilakukan pengujian pada sistem dengan perubahan set point berupa fungsi step dengan menaikkan suhu dari suhu $338,15 \mathrm{~K}$ menjadi $355,15 \mathrm{~K}$ pada waktu $\mathrm{t}=$ 1 menit dilanjutkan menurunkan suhu menjadi 340,15 pada waktu $\mathrm{t}=75$ menit dan mengubahnya lagi menjadi $350,15 \mathrm{~K}$ pada $\mathrm{t}=120$ menit, serta adanya gangguan sebagai perubahan suhu air masuk 
(To) berupa fungsi step dari suhu 303,15 K berubah menjadi $318,15 \mathrm{~K}$ pada $\mathrm{t}=30$ menit dan dilanjutkan berubah menjadi $293,15 \mathrm{~K}$ pada $\mathrm{t}=95$ menit

Tabel 2. Parameter Pengendali yang Disetel dengan Metode Optimasi

\begin{tabular}{|c|c|c|c|}
\hline $\begin{array}{c}\text { Simulasi } \\
\text { No }\end{array}$ & kc & $\boldsymbol{\tau}_{\mathbf{i}}$ & $\mathbf{T}_{\mathbf{d}}$ \\
\hline 1 & 199910 & 6,9668 & 0,6518 \\
\hline 2 & 173480 & 8,0601 & 0,6572 \\
\hline 3 & 195720 & 11,0548 & 0,6654 \\
\hline 4 & 124940 & 6,9668 & 0,6518 \\
\hline 5 & 247020 & 8,6177 & 0,6593 \\
\hline
\end{tabular}
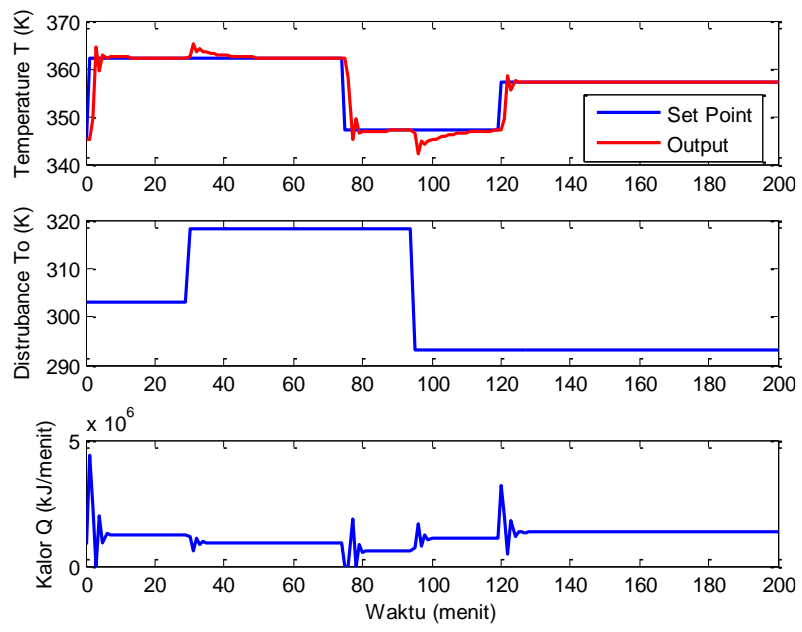

Gambar 4. Profil output dan kalor hasil perubahan set point dan gangguan dengan metode optimasi - Sistem 1.
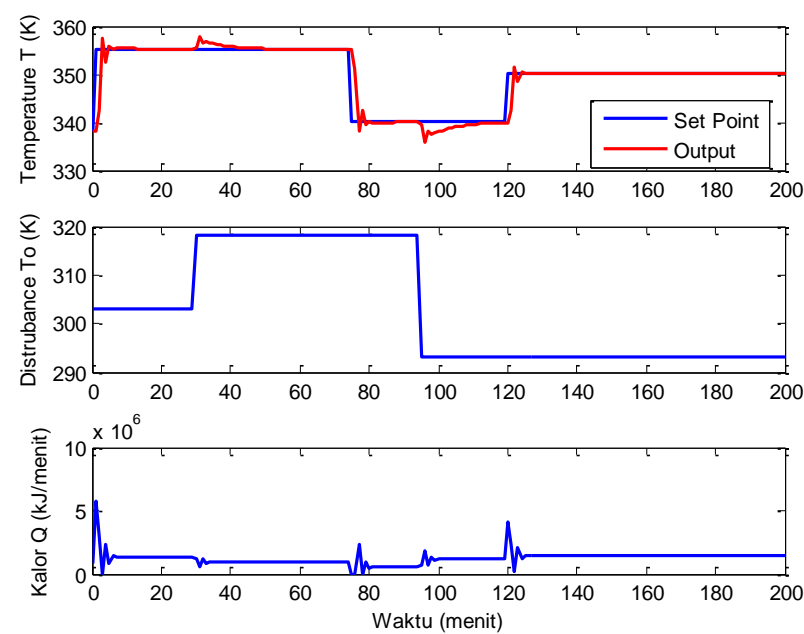

Gambar 5. Profil output dan kalor hasil perubahan set point dan gangguan dengan metode optimasi - Sistem 2
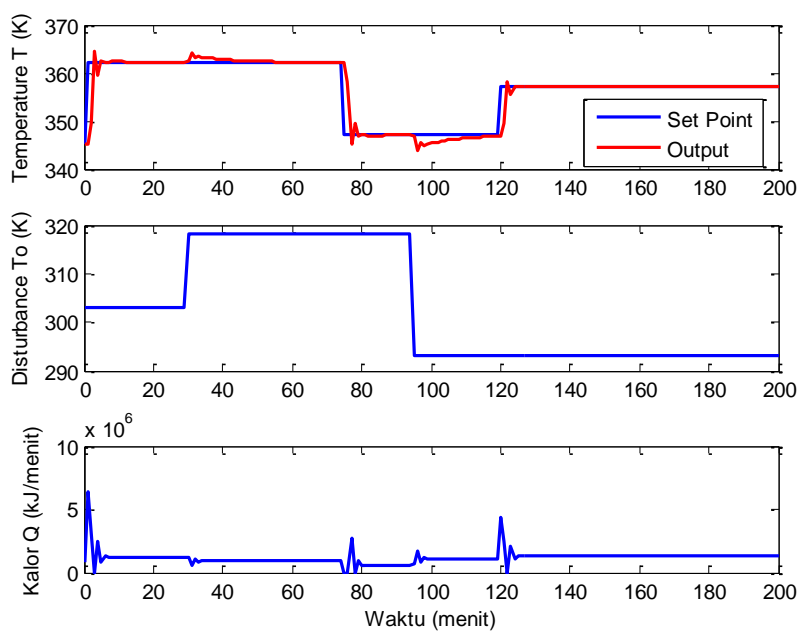

Gambar 6. Profil output dan kalor hasil perubahan set point dan gangguan dengan metode optimasi - Sistem 3
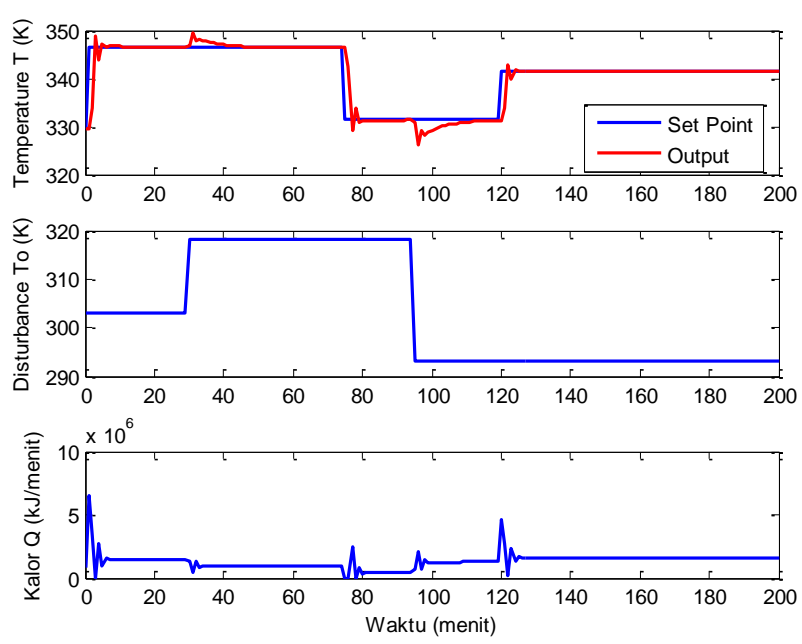

Gambar 7. Profil output dan kalor hasil perubahan set point dan gangguan dengan metode optimasi - Sistem 4
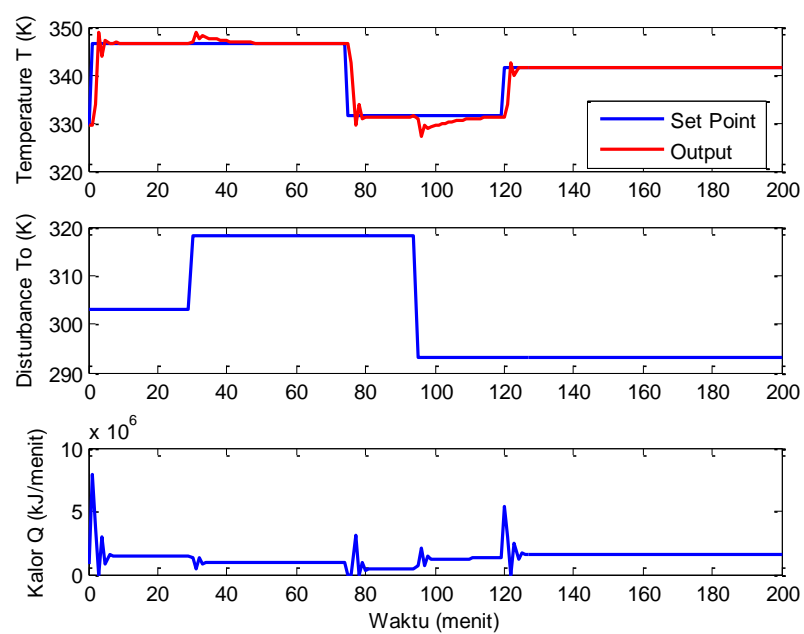

Gambar 8. Profil output dan kalor hasil perubahan set point dan gangguan dengan metode optimasi - Sistem 5 
Demikian dilakukan juga pengujian pada Sistem 3 s.d 5 seperti ditunjukkan pada Gambar 6 s.d 8. Pada kelima sistem tersebut, kenaikkan suhu set point akan menyebabkan jumlah kalor yang disuplai ke dalam tangki harus ditambah agar suhu keluar dapat mencapai seperti set point atau mencapai suhu yang diinginkan, begitu pula sebaliknya. Selain itu adanya gangguan berupa perubahan suhu masuk (To) akan menyebabkan jumlah kalor yang disuplai berubah.

Tabel 3 menampilkan harga SSE (sum squared of error) yang diperoleh pada kelima sistem yang ditinjau ketika disetel dengan metode optimasi. Harga SSE pada tabel tersebut dibandingkan dengan harga yang diperoleh ketika dicoba dengan metode penyetelan yang lain (yaitu Direct Synthesis dan Ziegler-Nichols). Tampak bahwa harga SSE yang diperoleh dengan metode optimasi adalah paling kecil jika dibandingkan dengan kedua metode yang lain (yang memang belum optimum). Detail tentang metode Direct Synthesis dan Ziegler Nichols dapat dilihat pada literature $[1,4]$.

Tabel 3. Nilai SSE

\begin{tabular}{|c|c|c|c|}
\hline \multirow{2}{*}{$\begin{array}{c}\text { Simulasi } \\
\text { No }\end{array}$} & \multicolumn{3}{|c|}{ SSE } \\
\cline { 2 - 4 } & Optimasi & $\begin{array}{c}\text { Direct } \\
\text { Synthesis }\end{array}$ & $\begin{array}{c}\text { Ziegler- } \\
\text { Nichol }\end{array}$ \\
\hline 1 & 1070,9 & 1565,9 & 1308,7 \\
\hline 2 & 1061,7 & 1555,4 & 1329,0 \\
\hline 3 & 1049,3 & 1372,0 & 1586,7 \\
\hline 4 & 1070,9 & 1565,9 & 1309,4 \\
\hline 5 & 1058,3 & 1555,6 & 1340,6 \\
\hline
\end{tabular}

\section{Kesimpulan}

Metode optimasi telah digunakan dalam penelitian ini untuk melakukan penyetelan pengendali PID pada sistem tangki pemanas berpengaduk. Optimasi menggunakan metode least square non linear merupakan metode efektif untuk menghasilkan nilai parameter pengendali PID terbaik. Hal ini terbukti melalui perbandingan dengan metode metode lain bahwa nilai SSE dari metode Optimasi paling kecil. Dari hasil penelitian tersebut terbukti bahwa dengan melakukan simulasi proses orde satu sistem lintas tertutup dengan pengendalian, hasil penyetelan metode Optimasi didapat output yang paling mendekati perubahan set point.

\section{Ucapan Terimakasih}

Penulis mengucapkan terimakasih kepada Universitas Surabaya (Ubaya) dan mahasiswa: Ronald Paulus dan Bob Sadewo yang telah membantu melakukan penelitian ini.

\section{Daftar Pustaka}

[1] D. Coughanowr, S.E LeBlanc, Process Systems Analysis and Control, 3rd ed, McGraw Hill, New York, 2009.

[2] T.F Edgar, D.M Himmelblau, Optimization of Chemical Processes, McGraw Hill, New York, 1989.

[3] J. A. Romero, R. Sanchis, P. Balaguer, Journal of Process Control, 21, (2011) 840-851.

[4] D.E Seborg, T.F Edgar, D.A Mellichamp, Process Dynamics and Control,John Wiley \& Sons, New York, 1989.

[5] G. Syrcos, I. K Kookos, Chemical Engineering and Processing, 44, (2005) 41-49.

[6] S. Tavakoli, M. Tavakoli. Department of Automatic Control and Systems Engineering, The University of Sheffield, 2003.

[7] R. Agustriyanto, A. Fatmawati, Prosiding Seminar Nasional Teknik Kimia Kejuangan, Yogyakarta, 2014. 